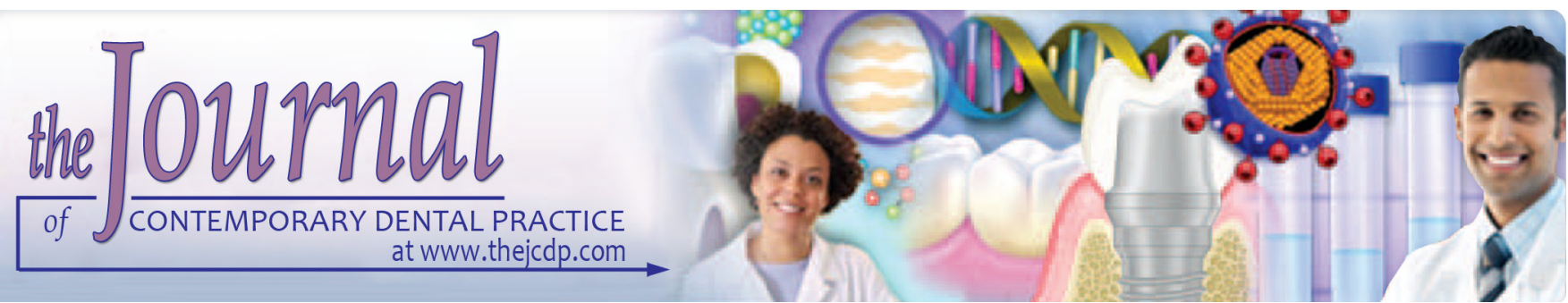

\title{
Clinical Outcomes of Low-level Laser Therapy in Management of Advanced Implant Surgery Complications: A Comparative Clinical Study
}

\author{
${ }^{1}$ Narges Pouremadi, ${ }^{2}$ Arash Motaghi, ${ }^{3}$ Roya Safdari, ${ }^{4}$ Paridokht Zarean, ${ }^{5}$ Ashkan Rashad, ${ }^{6}$ Parichehr Zarean, \\ ${ }^{7}$ Shahram Aminy
}

\begin{abstract}
Introduction: Nowadays, implant insertion is accompanied by undesired consequences. As surgery techniques become more and more complex, an increase of intra- and post-op complications can be expected. Application of low-level laser (LLL) is one of the conservative approaches to control the complications with any side effects and low treatment costs. The present study aimed to evaluate the effect of $650 \mathrm{~nm}$ LLL irradiation on the reduction of complications after advanced implant surgeries.
\end{abstract}

Materials and methods: In this triple-blinded clinical trial, 30 patients aged between 25 to 65 years were in need of bone graft or sinus lift procedure for simultaneously implant insertion. In the LLL treatment group, the surgical site of each implant was treated with $650 \mathrm{~nm}$ laser. The same method and duration were applied in the placebo group. The pain levels, facial swelling, and wound healing were evaluated.

Results: This study indicated that pain levels were reduced in the laser group $(p<0.05)$. Also, facial swelling in the $3 \mathrm{rd}$ and 7 th day after the surgery relieved more in laser group. Furthermore, investigation of the surgical site showed a higher level of wound healing in the laser group $(p<0.05)$.

Conclusion: Regarding the biological effects of advanced implant surgeries and accompanying complications, adjuvant

\footnotetext{
1,3 Isfahan (Khorasgan) Branch, Islamic Azad University, Isfahan, Islamic Republic of Iran

${ }^{2}$ Department of Oral medicine, Isfahan (Khorasgan) Branch, Islamic Azad University, Isfahan, Islamic Republic of Iran

${ }^{4}$ Dental Implants Research Center, School of Dentistry, Isfahan University of Medical Scieneces, Isfahan, Islamic Republic of Iran

${ }^{5}$ Department of Oral and Maxillofacial Surgery, University Medical Center Hamburg-Eppendorf, Hamburg, Germany

${ }^{6}$ Dental Research Center, School of Dentistry, Isfahan University of Medical Scieneces, Isfahan, Islamic Republic of Iran

${ }^{7}$ Department of Periodontology, Isfahan (Khorasgan) Branch, Islamic Azad University, Isfahan, Islamic Republic of Iran

Corresponding Author: Roya Safdari, Isfahan (Khorasgan) Branch, Islamic Azad University, Isfahan, Islamic Republic of Iran, Mobile: +989133190901, e-mail: Safdari.roya@yahoo.com
}

treatment with a laser could significantly improve wound healing and reduce the severity and duration of pain and swelling.

Clinical significance: This clinical trial demonstrates reductions of the level of pain, facial swelling and improvements of wound healing are followed by the use of low-level laser therapy.

Keywords: Dental implant, Edema, Low-level laser therapy, Pain control, Wound healing.

How to cite this article: Pouremadi N, Motaghi A, Safdari R, Zarean P, Rashad A, Zarean P, Aminy S. Clinical Outcomes of Low-level Laser Therapy in Management of Advanced Implant Surgery Complications: A Comparative Clinical Study. J Contemp Dent Pract 2019;20(1):78-82.

Source of support: Nil

Conflict of interest: None

\section{INTRODUCTION}

Currently, reconstruction of bone defects, obtain of optimum esthetic appearance and reduction of treatment time are three major aims in implantology. The main issues in advanced implant surgeries are guided bone regeneration (GBR), bone grafts in the maxillary sinus, bone block grafts and bone split and expansion. ${ }^{1-5}$ In the last 10 years, GBR technique became the standard treatment for reconstruction of localized bone defects in implantology. To date, the only other evidenced-based surgical treatment is sinus lift technique. ${ }^{6}$

Like any other therapeutic method, side effects and complications are an impartible part of implant treatment. Even if success rates of osseointegrated implants is reported to be above $90 \%$, failure of implants represent an unpleasant condition for the patient as well as for the practitioner. But as techniques to be used for reconstruction become more and more complex, an increase of intra- and post-op complications can be expected. ${ }^{7-9}$ For instance, peri-implant tissue is 
traumatized in most implant surgeries and therefore causes varying degrees of inflammatory reactions. By controlling the inflammation, common complications after surgery like swelling, trismus, pain, and infection can be reduced. ${ }^{10}$

Care instructions after the surgery are one of the most important factors in reach successful treatment. ${ }^{6}$ Use of low-level laser is one of the relatively new and conservative methods to control the above-mentioned side effects in recent years. From the beginning of understanding the effects of LLLT like analgesic, antiinflammatory, anti-edema, wound healing, it stimulates the immune system which finally causes the regular physiological condition of the tissue. Due to the special biological condition of the oral cavity, LLLT is widely used in different fields of dentistry. ${ }^{11,12}$

There are various studies about the use of LLLT in order to control the complications of oral surgeries, especially in impacted wisdom teeth extraction surgeries. Also, there are some studies that reported positive effects of the above-mentioned method on bone-titanium integration. ${ }^{13-15}$ But till now, to the best of our knowledge, there is not any clinical trial that evaluates LLLT effects on complication management in implant surgeries. Therefore, in this study, we sought to evaluate the effect of $650 \mathrm{~nm}$ laser at surgical sites after complications occurred in oral implant treatment.

\section{MSATERIALS AND METHODS}

In this triple-blinded clinical trial 30 patients (15 male, 15 female) aged between 25-65 years were selected. The patients required bone grafting or sinus lift procedure for implant insertion at the same session beginning from January 2015-January 2017 at our university dental department. Also, informed written consent explaining the methodology, potential clinical benefits, and possible side effects were obtained from all patients. Ethical approval has been granted by the Ethics Committee of Medical University (Ethical approval number 493039).

The study was triple-blinded by allocating the first investigator for synchronization of patients groups and laser radiation (only this first investigator knew which patients belonged to the case or placebo group). The second investigator was unaware of the first investigator's task and consequently did not know which patient was designed for which group. He documented clinical measurements and processed questionnaires of the research. It should be noted that the surgeon and data analyzer were blinded to the patient's group allocation. The patients could not realize whether laser instruments were on or off by the use of laser protective glasses.

\section{Inclusion Criteria}

It involved patients with healthy oral mucosa, without active systemic disorder or disease, without contraindications for implant insertion such as diabetes; and required bone grafting or sinus lift coincide with implant insertion in one session.

\section{Exclusion Criteria}

Lack of patient's cooperation, history of implant failure in the site of insertion, pregnancy, photosensitivity, history of medical conditions with potential delay of wound healing (e.g., diabetes), smokers, alcohol abusers, patients who have used antibiotics and corticosteroids with any reason during two weeks before surgery.

Selected patients were divided into case and control (placebo) groups. They were synced based on age, sex, surgical method, site of surgery and experience of oral and maxillofacial surgeon. Numbers of cases were achieved according to calculations of statistical counselee with 0.5 error rate and 0.42 accuracy. All of the allografts used for all patients were from ITB $^{1}(0.5$ cc packed $300-800$ micrometer freeze-dried).

A $650 \mathrm{~nm}$ laser and the module of low power diode laser were used (Exi Laser Co, USA). To ensure the continuous exposure and to determine the output power of device, we received SAIRAN electro-opic industries (sa IRAN co.) approval.

For each patient in the laser group, the surgical site of the implant was irradiated from buccal and lingual individually. The laser was used with $650 \mathrm{~nm}$ wavelength, continuous and 55 MW power by the circular crosssection and $0.7 \mathrm{~cm}$ diameter probe. The effective dose for laser therapy and exposure time were $5 \mathrm{j} / 2 \mathrm{~cm}$ and 35 seconds, respectively (Fig. 1).

For every 30 minutes of laser function, the output power was tested without any noted changes. The patients were asked to follow the common instructions after implant insertion as below:

- Capsule Amoxicillin 500 mg q8h, Tablet Metronidazole $250 \mathrm{mg}$ q8h for 7 days for all patients.

- Tablet Ibuprofen $400 \mathrm{mg}$ prescribed for the first days after treatment if the pain was manifest.

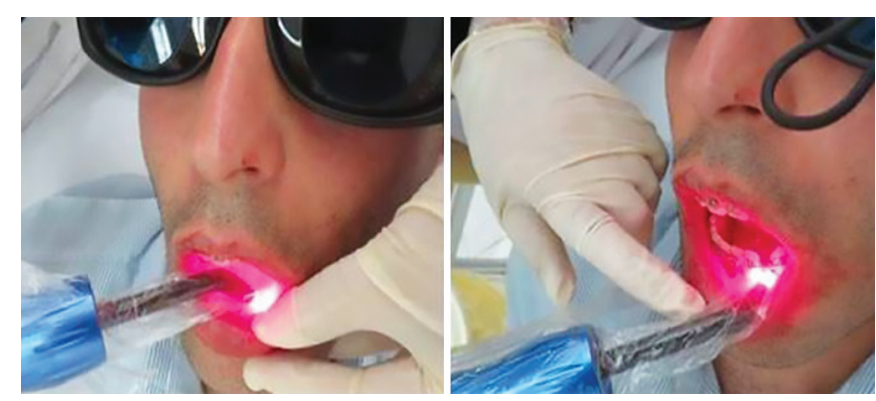

Fig. 1: Immediate exposure of implant surgical site from lingual (left) and buccal side (right) 
Table 1: Mean of VAS in different times

\begin{tabular}{|c|c|c|c|c|c|c|c|c|}
\hline \multirow[b]{2}{*}{ Group } & \multicolumn{2}{|c|}{$\begin{array}{l}\text { After } \\
12 \text { hours }\end{array}$} & \multicolumn{2}{|c|}{$\begin{array}{l}\text { After } \\
24 \text { hours }\end{array}$} & \multicolumn{2}{|c|}{$\begin{array}{l}\text { After } \\
48 \text { hours }\end{array}$} & \multicolumn{2}{|c|}{$\begin{array}{l}\text { After } \\
72 \text { hours }\end{array}$} \\
\hline & Mean & $S D$ & Mean & $S D$ & Mean & $S D$ & Mean & $S D$ \\
\hline Placebo & 4.5 & 2.53 & 2.53 & 1.59 & 2.2 & 0.75 & 0.8 & 0.36 \\
\hline Laser & 1.7 & 0.51 & 0.46 & 0.23 & 0.06 & 0.06 & 0 & 0 \\
\hline $\mathrm{P}$-value & $0.001>$ & & $0.001>$ & & 0.02 & & 0.02 & \\
\hline
\end{tabular}

A single dose of $8 \mathrm{mg} / 2 \mathrm{~mL}$ dexamethasones prescribed intramuscular injection for all patients immediately after surgery.

Use of cold compress (ice pack) in the site of surgery, 20 minutes per hours intermittently for 24-36 hours after the surgery.

Control the plaque by use of chlorhexidine $(0.12 \%)$ mouthwash for two weeks.

Laser radiations to surgical sites were applied immediately, 72 hours and one week after the surgery. In placebo group, all procedures were same but with an off laser. The amount of pain was registered 12, 24, 48 and 72 hours after the surgery with the VAS questionnaire ( 0 for no pain and 10 for deadly pain).

To measure the degree of inflammation, we used a clinical method. In this method, five facial landmarks such as mid of the tragus, gonion and pogonion of soft tissue, lip commissure, and outer canthus of the eye were considered to measure three lines of tragus to pogonion, outer canthus of the eye to gonion and tragus to lip commissure, as a base value for inflammation assessment (Fig. 2). The differences between the three mentioned lines, before surgery, 3 and 7 days after the implant insertion should represent amount of inflammation.

The healing process was graded into five degrees: " 0 " for complete healing, " 1 " for obvious healing and a thin line of fibrin layer, " 2 " for healing and obvious fibrin, " 3 " for incomplete healing (dehiscence) and " 4 " for flap necrosis. According to mentioned grades, we

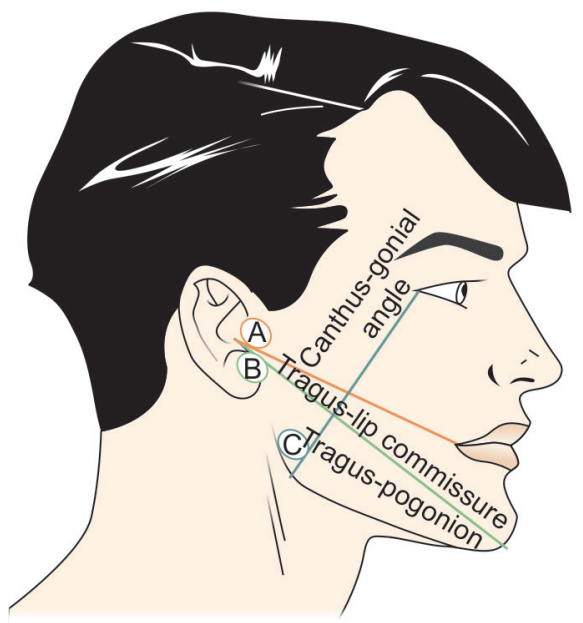

Fig. 2: (A) Tragus to lip commissure; (B) Outer canthus of the eye to gonion; (C) Tragus to pogonion
Table 2: Mean time of pain elimination and analgesic consumption

\begin{tabular}{llllll}
\hline & \multicolumn{2}{c}{ Placebo } & \multicolumn{2}{c}{ Laser } & \\
\cline { 2 - 5 } Variables & Mean & $S D$ & Mean & $S D$ & p value \\
\hline Pain less time & 57.2 & 5.93 & 19.6 & 4.11 & $<0.001$ \\
$\begin{array}{l}\text { Analgesic } \\
\text { consumption }\end{array}$ & 5 & 1.22 & 2.73 & 2.4 & 0.1 \\
\hline
\end{tabular}

recorded investigations on 3rd, 7th and 14th day after implant insertion.

T-test and $\mathrm{K}^{2}$ tests were used to compare the duration and severity of pain, the amount of analgesic consumption and inflammation. Mann-Whitney test was used to compare the healing degree between laser and placebo groups. Finally, the obtained data were analyzed by use of SPSS 21 (Chicago, USA).

\section{RESULTS}

Mean age of the placebo groups were $44.8( \pm 12.5)$ and $44( \pm 11.7)$ years of age respectively. Therewerenosignificant differences between both groups $(p=0.86)$. Frequency distribution of sex $(p=0.37)$, jaw (maxilla or mandible) $(p=0.9)$ and surgical techniques (GBR/sinus lifting) $(p=1)$ were also statistically not significantly different between both groups.

The mean of VAS in the laser group in comparison with placebo group was significantly reduced at different times after the surgery (Table 1).

The mean time of pain elimination after the surgery was significantly lower in the laser group $(p<0.001)$. But there were no significant differences in analgesic consumption between laser and placebo group $(p=0.1)$ (Table 2).

Primary index of the face before surgery (sum of three lines such as tragus to pogonion, outer canthus of the eye to gonion and tragus to lip commissure, as a base value for inflammation assessment), amount of inflammation after 72 hours and 1 week, were assessed. Table 3 outlines the results of the study.

There were no significant differences in the primary index of face inflammation in laser and placebo group before $(p=0.85)$ and 72 hours after the implant insertion $(p=0.48)$. But inflammation value reduced significantly one week after surgery $(p=0.007)$.

Table 3:The mean amount of inflammation

\begin{tabular}{|c|c|c|c|c|c|}
\hline \multirow[b]{2}{*}{ Variables } & \multicolumn{2}{|c|}{ Placebo } & \multicolumn{2}{|c|}{ Laser } & \multirow[b]{2}{*}{$p$ value } \\
\hline & Mean & $S D$ & Mean & $S D$ & \\
\hline Primary index of face & 36.1 & 2.2 & 36.2 & 2.5 & 0.85 \\
\hline $\begin{array}{l}\text { Amount of inflammation in } \\
72 \text { hours }\end{array}$ & 1.2 & 0.6 & 1.03 & 0.7 & 0.48 \\
\hline $\begin{array}{l}\text { Amount of inflammation in } \\
\text { a week }\end{array}$ & 0.53 & 0.1 & 0.18 & 0.1 & 0.007 \\
\hline
\end{tabular}


Clinical Outcomes of Low Level Laser Therapy

\begin{tabular}{|c|c|c|c|c|c|c|c|c|c|c|}
\hline & \multicolumn{2}{|c|}{ Complete healing } & \multicolumn{2}{|c|}{ Grade 1 healing } & \multicolumn{2}{|c|}{ Grade 2 healing } & \multicolumn{2}{|c|}{ Grade 3 healing } & \multicolumn{2}{|c|}{ Grade 4 healing } \\
\hline & Laser & Placebo & Laser & Placebo & Laser & Placebo & Laser & Placebo & Laser & Placebo \\
\hline 3rd day & 0 & 0 & 33.3 & 0 & 66.7 & 46.7 & 0 & 46.7 & 0 & 6.7 \\
\hline 7th day & 13.3 & 0 & 60 & 26.7 & 26.7 & 46.7 & 0 & 20 & 0 & 6.7 \\
\hline 14th day & 66.7 & 13.3 & 26.7 & 33.3 & 6.7 & 46.7 & 0 & 6.7 & 0 & 0 \\
\hline
\end{tabular}

Healing degree was significantly different in 3rd, 7th and 14th day after implant insertion between both groups ( $p<0.001, p=0.004$ and $p=0.001$ respectively) (Table 4).

\section{CONCLUSION}

Despite the wide range of high power laser applications in surgery, there is little information about low-level lasers. Because of the laser varieties, the exact parameters of laser for achieving best results in healing improvement, pain and inflammation control are still not obvious in clinical trials.

The results of our study revealed that despitethe same consumption of analgesic, a significant reduction in pain severity and duration were seen in the laser group. Merigo et al., ${ }^{16}$ Kazancioglu et al., ${ }^{17}$ Saber et al., ${ }^{18}$ and Markovic' et al. ${ }^{19}$ reported similar results with significant reduction of pain after application of LLLT in various sites of the oral cavity.,The laser could reduce pain by modification of central and peripheral neural networks, lowering the action potential, inhibition of painful stimulations, increasing the pain threshold and balancing the action of adrenalin-noradrenalin. Direct inhibition of afferent peripheral neurons also leads to limiting $\mathrm{A}$ and $\mathrm{C}$ fibers and more releasing of neurokins. ${ }^{20}$ On the other hand, Ferrante et al., ${ }^{21}$ López ${ }^{22}$ and Paschoal et al. ${ }^{23}$ did not report any significant decrease in pain even if pain reduction was observed. It could be due to different laser wavelengths, variable laser parameters and different experimental design such as examination days and sample size.

Laser modifies the prostaglandin syntheses, inhibits the bradykinin syntheses, improves the phagocytosis, and lymphatic circulation and stimulates vasodilation. So it can affect the three phases of inflammation consequently and thereupon decrease in swelling is expected. ${ }^{11}$

Facial swelling in 7th day after implant insertion was significantly decreased. However, after 3rd day no significant reduction was seen. It can be a proof for this claim that the photochemical effect of LLLT is effective but need a renewal session to complete the inhibition of inflammation. These results are consistent with Merigo et al., ${ }^{16}$ Kazancioglu et al., ${ }^{17}$ Ferrante et al., ${ }^{21}$ and Aras et al. ${ }^{24,25}$ studies. It should be noted that the biologic effects of laser remain for about 72 hours. This fact is a criterion for cession intervals, and it could be concluded that a renewal in 3rd day after surgery is necessary to achieve a significant decrease in swelling. So we conclude that radiation in 3rd day after surgery is effective in the continuance of swelling reduction and following that significant wellness were noticed in 7th day after the surgery. The study of López et al..$^{22}$ revealed that swelling was slightly decreased in 2nd and 7th day after a surgical procedure but statistically non-significant. The reason could be because of the use of a laser on the border of high and low power irradiation that can limit the photochemical effects of low-level lasers. Markovic' et al. ${ }^{19}$ assumed that use of a low-level laser with corticosteroids could reduce swelling synergistically. Ferrante et al. ${ }^{21}$ and Aras et al. ${ }^{24,25}$ studies suggested less swelling by extraoral application rather than intraoral. According to Markovi et al. ${ }^{19}$ and our study results, it seems that the most effects of infra-red to the red laser at 4 to $6 \mathrm{j} / \mathrm{cm}^{2}$ density could be achieved. In our study, the efficacy of LLLT was improved with intraoral radiation immediately after the surgery and at 3rd day, contact of the probe to the site, application of extraoral irradiation at the insertion of masseter, topical use of corticosteroid.

Healing degree was significantly better in laser group at $3 \mathrm{rd}, 7$ th and 14th day after implant insertion. This is in accordance with results of in vivo and in vitro studies that represent the stimulating effects of LLLT on fibroblasts, keratinocytes, angiogenesis and releasing the growth factors. Moreover, LLLT could modify primary stages of cell adherence and the growth of fibroblasts on the titanium surface. ${ }^{20,26}$ However there is no study on the direct effect of LLLT on the oral flap (primary healing), but in vivo and in vitro studies suggested the use of LLLT after gingivectomy and gingivoplasty due to accelerating the secondary healing process. ${ }^{24,27}$

\section{CLINICAL SIGNIFICANCE}

Under consideration of the present study limitations, it seems that LLLT could impressively reduce the severity and duration of pain and swelling, and improve wound healing. Due to the great diversity of variables of the laser devices, we suggest an assessment of multiple parameters of radiation in future studies.

\section{REFERENCES}

1. Lotf Azar M. A colour atlas of advanced implant surgeries. 1st ed. Tehran, Iran:Shayannemoodar Publications 2009; 4,29,33,34,115. [In Persian]

2. Hermann JS, Buser D. Guided bone regeneration for dental implants. CurrOpin Periodontal 1996;3:168-177. 
3. Nevins M, Mellonig JT. Implant Therapy. Clinical Approaches and Evidence of Success.Tokyo, Japan Quintessence 1998;53-81.

4. Jensen OT. The sinus bone graft. Quintessence publication Co. UK2006;3-12.

5. Boyne PJ, James RA.Grafting of the Maxillary Sinus Floor with Autogenous Marrow and Bone. J oral Surg 1980;38:613616.

6. Gholami G, EsmaeelNejad A, TalebiArdakani M, TabibZadehNoori Z, Aghaloo M, AlizadehTabari Z. Fundamentals of Guided bone Regeneration. 1st ed. Tehran, Iran: Shayannemoodar publications 2013;14,77,100,156. [in Persian]

7. Stuart J. Dental Implant Complications: Etioloy, Prevention, and Treatment. First edition. Chichester: wiley-blackwell 2010;1.

8. Moraschini V, Poubel LA, Ferreira VF, Barboza Edos S. Evaluation of survival and success rates of dental implants reported in longitudinal studies with a follow-up period of at least 10 years: a systematic review. Int J Oral Maxillofac Surg 2015 Mar;44(3):377-388.

9. Busenlechner D, Fürhauser R, Haas R, Watzek G, Mailath G, Pommer B. Long-term implant success at the Academy for Oral Implantology: 8-year follow-up and risk factor analysis. J Periodontal Implant Sci 2014 Jun;44(3):102-108.

10. Mish CE. Contemporary Implant Dentistry. 3rd ed. St. Louis: Mosbyelsevier 2008;467,474-478.

11. Eghbali F. Application of low level laser in dentistry. 1st ed. Tehran, Iran: Shayannemoodar Publications 2010;20,24-37,54, 61-64,72,97,123,124,141. [in Persian]

12. MoritzA.Oral laser application.Berlin, Germany:Quintessence Publishing Company 2006;523-527.

13. de Vasconcellos LM, Barbara MA, da Rovai ES, de Oliveira França M, Ebrahim ZF, de Vasconcellos LG, et al. Titanium scaffold osteogenesis in healthy and osteoporotic rats is improved by the use of low-level laser therapy (GaAlAs). Lasers Med Sci 2016 Jul;31(5):899-905.

14. Kim JR, Kim SH, Kim IR, Park BS, Kim YD. Low-level laser therapy affects osseointegration in titanium implants: resonance frequency, removal torque and histomorphometric analysis in rabbits. J Korean Assoc Oral MaxillofacSurg 2016 Feb;42(1):2-8.

15. Prados-Frutos JC, Rodríguez-Molinero J, Prados-Privado M, Torres JH, Rojo R. Lack of clinical evidence on low-level laser therapy (LLLT) on dental titanium implant: a systematic review. Lasers Med Sci 2016 Feb;31(2):383-392.

16. Merigo E, Vescovi P, Margalit M, Ricotti E, Stea S, Meleti $\mathrm{M}$, et al. Efficacy of LLLT in swelling and pain control after the extraction of lower impacted third molars.LaserTher 2015;24(1):39-46.

17. Kazancioglu HO, Ezirganli S, Demirtas N. Comparison of the influence of ozone and laser therapies on pain, swelling, and trismus following impacted third-molar surgery. Lasers Med Sci 2014;29(4):1313-1319.

18. Saber K, Chiniforush N, Shahabi S. The effect of low level laser therapy on pain reduction after third molar surgery. Minerva Stomatol2012;61(7-8):319-322.

19. Marković AB, Todorović L. Postoperative analgesia after lower third molar surgery:contribution of the use of longacting local anesthetics, low-power laser, and diclofenac. Oral Surg Oral Med Oral Pathol Oral RadiolEndod 2006;102(5): e4-e8.

20. Convissar RA. Principles and practice of laser dentistry. 1sted. St. Louis: Elsevier Health Sciences 2011;272,274.

21. Ferrante M, Petrini M, Trentini P, Perfetti G, Spoto G. Effect of low-level laser therapy after extraction of impacted lower third molars. Lasers Med Sci 2013;28(3):845-9.

22. López-Ramírez M, Vílchez-Pérez MA, Gargallo-Albiol J, Arnabat-Domínguez J, Gay-EscodaC. Efficacy of low-level laser therapy in the management of pain, facial swelling, and postoperative trismus after a lower third molar extraction. A preliminary study. Lasers Med Sci 2012;27(3):559-566.

23. Paschoal MA, Santos-Pinto L. Therapeutic effects of lowlevel laser therapy after premolar extraction in adolescents: a randomized double-blind clinical trial.Photomed Laser Surg 2012;30(9):559-564.

24. Aras MH, Gungormus M. The effect of low-level laser therapy on trismus and facial swelling following surgical extraction of a lower third molar.Photomed Laser Surg 2009;27(1): 21-24.

25. Aras $\mathrm{MH}$, Güngörmüş $\mathrm{M}$. Placebo-controlled randomized clinical trial of the effect two different low-level laser therapies (LLLT)--intraoral and extraoral-on trismus and facial swelling following surgical extraction of the lower third molar. Lasers Med Sci 2010;25(5):641-645.

26. Ozcelik O, CenkHaytac M, Kunin A, Seydaoglu G. Improved wound healing by low-level laser irradiation after gingivectomy operations: a controlled clinical pilot study. J ClinPeriodontol 2008;35(3):250-254.

27. Mârțu S, Amălinei C, Tatarciuc M, Rotaru M, Potârnichie O, Liliac L. Healing process and laser therapy in the superficial periodontium: a histological study. Rom J MorpholEmbryol 2012;53(1):111-116 